\title{
COBRANÇA PELO ABASTECIMENTO DE ÁGUA NO RJ: REFLEXOS NA INADIMPLÊNCIA E NA INSATISFAÇÃO DOS USUÁRIOS COM O SERVIÇO
}

\section{COLLECTION FOR WATER SUPPLY IN RJ: REFLECTIONS IN DEFAULT AND USERS' DISSATISFACTION WITH THE SERVICE}

\author{
Patrícia Finamore Araujo ${ }^{(1)}$ \\ Engenheira Ambiental pela Universidade Federal de Viçosa (UFV), Msc. Saúde Pública pela Escola Nacional de Saúde \\ Pública (ENSP/FIOCRUZ), Doutoranda do Programa de Pós-Graduação em Urbanismo da Universidade do Rio de \\ Janeiro (PROURB/FAU/UFRJ). Pesquisadora do Laboratório de Estudos das Águas Urbanas (LEAU). \\ Ana Lucia Nogueira de Paiva Britto \\ Geógrafa pela Pontíficia Universidade Católica (PUC-RJ), Doutora em Urbanismo pelo Institut D'Urbanisme de Paris - \\ Université de Paris XII (Paris-Val-de-Marne), Professora do Programa de Pós-Graduação em Urbanismo da Universidade \\ do Rio de Janeiro (PROURB/FAU/UFRJ). Coordenadora do Laboratório de Estudos das Águas Urbanas (LEAU).
}

\section{E-mail ${ }^{(1)}$ : patricia.finamore @yahoo.com.br}

\section{RESUMO}

O objetivo do trabalho foi avaliar reclamações em canais de atendimento voltados para a defesa do consumidor feitas por usuários dos sistemas de abastecimento de água no Estado do Rio de Janeiro, a fim de ampliar as discussões sobre inadequações de práticas de cobrança que acabam por prejudicar ou até mesmo impedir o acesso à água, sobretudo de populações mais vulneráveis. As principais causas de insatisfação identificadas são decorrentes de aumentos inesperados na conta de água, que levam à desconfiança nos mecanismos de medição do volume consumido, à inadimplência e ao endividamento de famílias. Alguns usuários apontam que os altos valores cobrados pressionam seus orçamentos familiares, ainda que seja oferecida a possibilidade de parcelamento dos débitos. Verificou-se que o serviço opera na lógica do consumo-cliente e, portanto, ao invés de ser vista como um serviço essencial, a água é tratada como uma mercadoria.

\section{ABSTRACT}

The main objective of this paper was to evaluate complaints at the service channels focused on consumer protection made by users of the water supply system in Rio de Janeiro State, in order to broaden the discussions about inadequacies in billing practices that end up harming or even preventing access to water, particularly for the most vulnerable populations. The main causes of dissatisfaction identified are due to unexpected increases in the water bill, which lead to distrust in the mechanisms for measuring the volume consumed, defaults, and indebtedness of families. Some users point out that the high amount charged put pressure on their family budgets, even though the possibility of debt installment payments is offered. It was found that the service operates in the consumption-customer logic and, therefore, instead of being seen as an essential service, water is treated as a commodity.
\end{abstract}

Palavras-chave: Inadimplência. Endividamento. Conta de água. Defesa do consumidor.

Key words: Default. Debt. Water bill. Consumer protection.

\section{INTRODUÇÃO}

A crise econômica agravada pela pandemia tem pressionado os orçamentos das famílias brasileiras e dificultado o pagamento de contas de serviços essenciais como água, luz e gás. $\mathrm{O}$ atual cenário de empobrecimento da população traz grandes desafios aos prestadores de serviços públicos, cuja maior 
parte das receitas provém das tarifas pagas pelos usuários. Segundo a Serasa (2021), em abril de 2021, 62,5 milhões de brasileiros possuíam contas em atraso e a inadimplência com contas de serviços públicos representava 22,3\% do total de débitos, alcançando em torno de $\mathrm{R} \$ 37$ milhões em dívidas.

Em 2019, a Companhia Estadual de Águas e Esgoto do Rio de Janeiro (CEDAE) era responsável pelo abastecimento de água de 64 dos 92 municípios do Estado do RJ, sendo que metade da população atendida encontra-se na cidade do Rio de Janeiro, onde cerca de 6 milhões de pessoas têm acesso às redes de distribuição de água. O índice de evasão de receitas [IN029], que traduz a inadimplência nos municípios, era de 20\% (BRASIL, 2019). Esclarece-se que o índice aponta os valores faturados (receita operacional) e não arrecadados, mas não o número de famílias que se encontram em situação de inadimplência.

O inadimplemento sujeita os usuários a penalidades e sanções, tais como multas e a interrupção dos serviços. Logo, a incapacidade de pagamento pode vir a impedir o acesso e a concretização do direito humano à água de uma parcela da população (ONU, 2010). A renda das famílias pobres varia muito ao longo do tempo, sobretudo em decorrência das condições de trabalho pautadas na informalidade, podendo ser insuficiente para arcar com as tarifas (BROWN\&HELLER, 2017). Mas há uma grande dificuldade em diferenciar quem realmente não tem capacidade de pagar e, portanto, se prejudica com a cobrança e interrupção do serviço, daqueles que não pagam por outros motivos.

O objetivo da pesquisa foi avaliar reclamações em canais de atendimento voltados para a defesa do consumidor feitas por usuários dos sistemas de abastecimento de água operados pela CEDAE, a fim de identificar questões críticas relacionadas à cobrança do serviço. Buscou-se evidenciar os principais conflitos entre os usuários e a prestadora, bem como ampliar as discussões sobre inadequações da política ou de práticas de cobrança que acabam por prejudicar ou até mesmo impedir o acesso à água, sobretudo de populações mais vulneráveis.

\section{METODOLOGIA}

A pesquisa se pautou no contraponto entre as práticas conduzidas pela concessionária dos serviços de abastecimento de água e as reclamações dos usuários. Foi feita uma busca por fontes primárias, sendo levantados os regulamentos estaduais e o material informativo exposto no site da companhia para descrever as práticas de cobrança adotadas. Já a insatisfação dos usuários com os serviços foi verificada a partir das reclamações feitas pelos mesmos nos canais de atendimento.

Diante de um problema no abastecimento, os usuários podem buscar: (i) os canais de atendimento da companhia de água; (ii) a Ouvidoria caso não obtenham êxito nos canais de atendimento; (iii) outros canais de atendimento que não os da companhia; ou (iv) múltiplos canais de atendimento. Esclarecese que há quem reclame em mais de um canal ou até mesmo mais de uma vez no mesmo canal. Logo, reconhece-se que embora importante para caracterizar preliminarmente a insatisfação dos usuários com o serviço, o quantitativo de reclamações é um dado possivelmente superestimado.

A CEDAE disponibiliza aos usuários, a depender da demanda, a possibilidade de serem atendidos via internet, telefone e/ou presencialmente em agências físicas. Quem procura solucionar seus problemas junto aos referidos canais, mas não obtêm êxito, têm ainda à disposição uma Ouvidoria que atua recebendo reclamações, solicitações, sugestões, denúncias, informações e elogios. Quem busca por canais externos de atendimento também é direcionado para a Ouvidoria. A Ouvidoria da CEDAE é, portanto, responsável pelo atendimento de primeira e segunda instância por meio de diversos canais (Quadro 1). 
Quadro 1 - Canais de entrada de demandas da Ouvidoria da CEDAE.

\begin{tabular}{|c|c|}
\hline $\begin{array}{l}\text { 1. Canais de entrada de } \\
\text { demandas de primeira instância }\end{array}$ & $\begin{array}{l}\text { 1.1. Atendimento Telefônico SAC (0800-2821195) } \\
\text { 1.2. Fale com a CEDAE (www.cedae.com.br) } \\
\text { 1.3. Documentos Físicos (a) } \\
\text { 1.4 - Ouvidoria do Ministério Público do Estado do Rio de Janeiro MPERJ } \\
\text { (ouvidoriamperj@ @edae.com.br) } \\
\text { 1.5 - Consumidor.gov (https://www.consumidor.gov.br) } \\
\text { 1.6 - Fala.BR (Governo da União) } \\
\text { 1.7 - NINA (www.cedae.com.br) } \\
\text { 1.8 - Reclame Aqui (www.reclameaqui.com.br) } \\
\text { 1.9 - Disque Denúncia } \\
\text { 1.10 - Comissão de Defesa do Consumidor da ALERJ - CODECON } \\
\text { 1.11 - Alô-ALERJ }\end{array}$ \\
\hline $\begin{array}{l}\text { 2. Canais de atendimento de } \\
\text { segunda instância - Ouvidoria }\end{array}$ & $\begin{array}{l}2.1 \text { - Atendimento Telefônico Ouvidoria }(0800-0316032) \\
2.2 \text { - E-mail (ouvidoriageral@ cedae.com.br) } \\
2.3 \text { - Atendimento Pessoal no prédio sede (que inclui atendimento e pré } \\
\text { atendimento) } \\
2.4 \text { - AGENERSA (cedae.agenersa@cedae.com.br) }\end{array}$ \\
\hline $\begin{array}{l}\text { 3. Canais de atendimento de } \\
\text { Acesso à Informação }\end{array}$ & $\begin{array}{l}\text { 3.1. E-SIC (GOV. DO ESTADO) } \\
\text { 3.2. SIC Presencial }\end{array}$ \\
\hline
\end{tabular}

NOTA: (a) documentos provenientes de: autos de infração da PMRJ; editais da Prefeitura do RJ; Câmara dos Deputados RJ; Câmara de Vereadores; SUBDEC; Registro de Documento; Carta s/no; Telegrama.

Fonte: Relatório de atendimento Ouvidoria $-1^{\circ}$ semestre de 2021. Disponível em: <https://storage.googleapis.com/sitecedae/ouvidoria/relatorios/semestrais/Relat\%C3\%B3rio\%20\%20Ouvidoria\%20-

$\% 201 \%$ C2\%BA\%20Semestre\%20de\%202021.pdf>

A fim de melhor caracterizar a insatisfação dos usuários, a pesquisa se pautou sobretudo no teor das reclamações feitas nos canais de atendimento. Para tanto, foram escolhidos os canais que permitiam a análise dos relatos na íntegra. São eles: as plataformas de resolução de conflitos entre consumidores e empresas 'Consumidor.gov' [1.5] e Reclame Aqui [1.8]. As reclamações foram categorizadas por tipo de demanda, com foco naquelas que questionavam as práticas de cobrança. Por fim, buscou-se identificar as circunstâncias relacionadas à cobrança que, na visão dos usuários, lhe causam prejuízos e são vistas como práticas injustas.

Cabe destacar que estes usuários são consumidores respaldados pelo Sistema Nacional de Defesa do Consumidor (SNDC), instituído pelo Código de Defesa do Consumidor (CDC - Lei no 8.078/1990) e regulamentado pelo Decreto $\mathrm{n}^{\mathrm{o}}$ 2.181/1997. O SNDC congrega Procons (estaduais e municipais), Ministério Público, Defensoria Pública e entidades civis de defesa do consumidor. Estes órgãos possuem competência concorrente e atuam de forma articulada e integrada com a Secretaria Nacional do Consumidor (SENACON) do Ministério da Justiça e Segurança Pública para receber denúncias, apurar irregularidades e promover a proteção e a defesa dos consumidores.

\section{RESULTADOS E DISCUSSÃO}

\subsection{Práticas de cobrança da CEDAE}

O regulamento dos serviços públicos de abastecimento de água e esgotamento sanitário do Estado do Rio de Janeiro é regido pelo Decreto Estadual no 553/1976. A estrutura tarifária para o consumo residencial adotada é pautada no modelo de blocos crescentes, muito difundido no Brasil, no qual são estabelecidas faixas de consumo mensal de água, com tarifas crescentes por $\mathrm{m}^{3}$ consumido para as faixas de maior consumo. Adota-se também a cobrança de um volume mínimo de $15 \mathrm{~m}^{3}$ mensais para as economias residenciais, que indica o limite de consumo que se atribui a uma conta cujo valor não 
se altera qualquer que seja o consumo efetivo, sendo cobrado mesmo que o imóvel esteja desocupado.

Para que esse modelo funcione, é preciso que haja hidrometração, ou seja, que o consumo de água seja medido. De acordo com o SNIS (2019) [IN009], 54,43\% das ligações ativas nos municípios atendidos pela CEDAE são hidrometradas. A fim de garantir o bom funcionamento dos equipamentos e em cumprimento à Portaria do INMETRO n 295/2018, a CEDAE realiza a substituição dos hidrômetros em prazo não superior a sete anos (ALERJ, 2020). Onde a medição do consumo é interrompida, a cobrança é feita a partir do consumo-base, que corresponde ao consumo médio apurado pelas leituras dos doze últimos meses. Ressalta-se que onde não há hidrômetros é feita a cobrança do volume mínimo, pois conforme a Lei Estadual nº 8.234/2018, as concessionárias de água, luz e gás são impedidas de estimar o consumo para fins de cobrança através do levantamento de áreas e cômodos nos imóveis dos consumidores.

A companhia informa que o corte de água - por selo, por obturador ou levantamento do ramal do imóvel - pode ocorrer por falta de pagamento, ligação clandestina, fornecimento de água para imóveis em situação irregular de abastecimento, desperdícios e outras infrações ao seu regulamento (CEDAE, 2018). O corte é realizado a partir do débito de três faturas. A inadimplência pode levar não apenas à interrupção do fornecimento, mas também à inscrição do titular da matrícula nos sistemas de proteção de crédito (negativação). Nesses casos, o usuário é incentivado à procurar as agências de atendimento para renegociar sua dívida. Observa-se que a alternativa dada para a inadimplência é o endividamento.

Durante a pandemia, foram suspensos o corte do abastecimento e da negativação de débitos dos clientes, foi permitido o parcelamento de débitos direto no endereço eletrônico da empresa, com isenção total de multas e foi prorrogado o vencimento das contas por 60 dias nos primeiros meses (março a junho de 2020) (Lei Estadual nº 8769/2020).

\subsection{Reclamações dos usuários}

A CEDAE figura entre as empresas mais acionadas nos Juizados Especiais Cíveis do Tribunal de Justiça do Estado do Rio de Janeiro (TJRJ), com 5.248 processos ajuizados no ano de 2018. Destacase que as concessionárias de energia, companhias telefônicas e bancos concentram a maior parte dos registros das empresas mais acionadas (TJRJ, 2019).

No Sistema Nacional de Informações de Defesa do Consumidor (SINDEC), onde são registradas as reclamações feitas ao PROCON, os serviços de água encontram-se entre os principais assuntos reclamados no ano corrente (2021), atrás apenas dos serviços de energia elétrica e telefonia celular. Nos últimos anos, a CEDAE sempre figurou entre as 15 empresas com maior número de reclamações, tendo sido feitos 763 atendimentos em 2018, 1.493 em 2019 e 964 em 2020, tanto no âmbito estadual quanto municipal. Em 2021, dos 678 atendimentos já realizados, 399 foram motivados por problemas relacionados à cobrança.

No primeiro semestre de 2021, a Ouvidoria da CEDAE recebeu em torno de 400 mil demandas, das quais $94 \%$ foram provenientes de canais de primeira instância. Verificou-se que cerca de 50 mil demandas, o que corresponde a 12,5\% do total, foram direcionadas ao Setor Comercial, referentes a questões de revisão de contas, alteração de nome na conta, e parcelamento/reparcelamento (CEDAE, 2021).

\section{Consumidor.gov}

Institucionalizada pelo Decreto $\mathrm{n}^{\circ} 8.573 / 2015$, a plataforma Consumidor.com foi desenvolvida pela SENACON objetivando viabilizar a negociação de conflitos de consumo notificados eletronicamente. Neste portal são reunidas informações que ficam disponíveis para a sociedade, permitindo conhecer a reputação da empresa, e para governos, que podem usá-los para balizar suas políticas de consumo. A participação das empresas na plataforma era voluntária, mediante assinatura de termo de adesão. 
No entanto, devido ao aumento expressivo de demandas consumeristas durante a pandemia, além da necessidade de distanciamento social neste período, o cadastro de empresas e grupos econômicos específicos passou a ser obrigatório conforme Portaria n ${ }^{\circ} 12$, de 05/04/2021.

Em 2021, foram registradas 775 reclamações na referida plataforma contra a CEDAE. Com a busca pelas palavras-chave 'fatura', 'cobrança' e 'conta' foram identificados 300 relatos relacionados à cobrança dos serviços. Em linhas gerais, os relatos se referem a: desconfiança do funcionamento do hidrômetro ou da leitura do equipamento; taxas adicionais de serviços de manutenção e instalação de medidores; insatisfação com as formas de cobrança (volume mínimo e estimativa); (re) parcelamento de dívida; contestação de valores tidos como abusivos; supressão de ramal; e manutenção da cobrança em caso de desabastecimento ou abastecimento precário.

Foi observado que as reclamações decorrentes da interrupção do serviço possuem naturezas opostas. Há os usuários que querem realizar a supressão do ramal, devido à mudanças, demolição do imóvel ou desocupação por tempo prolongado, e pretendem não arcar mais com a cobrança. Há ainda aqueles insatisfeitos com o serviço e, por isso, querem se desconectar da rede. A prestação é mantida, assim como a cobrança, o que motiva a reclamação. Por outro lado, há os que sofrem as sanções decorrentes do não pagamento e são privados do serviço, e ficam insatisfeitos por não poderem contar com ele, embora necessitem.

Verificou-se que são recorrentes reclamações motivadas por aumentos repentinos da conta. Nesses casos, a insatisfação é direcionada para as formas de medição e cobrança. Há quem aponte que embora possua hidrômetro, não tem sua cobrança pautada pela medição real do equipamento, sendo feita uma estimativa de consumo a partir de medições anteriores ou pelo volume mínimo. Em imóveis fechados, sem uso de água, essa prática fica mais evidente. Por outro lado, há quem solicite a verificação da média de consumo anterior para comprovar consumos injustificados muito acima dela. A companhia informa, na própria plataforma, que em caso de consumo atípico do imóvel, cujo aumento ultrapassa em $100 \%$ a média dos 12 meses anteriores, as contas podem ser refaturadas considerando a média anterior acrescida de $50 \%$.

\section{Site Reclame Aqui}

A plataforma Reclame Aqui funciona desde 2001 na resolução de conflitos entre consumidores e empresas da América Latina. A partir dela os usuários podem, de forma gratuita, enviar reclamações e pesquisar a reputação e a experiência de outros consumidores com as empresas. No último ano [01/10/2020 a 30/09/2021] foram registrados 1.570 reclamações contra a CEDAE no site, sendo que 566 delas ocorreram nos últimos seis meses [01/04/2021 a 30/09/2021].

Foi verificado que a maior quantidade das reclamações na plataforma são motivadas por falta de água e insatisfação com a qualidade da água distribuída. Segundo os reclamantes, a água apresentava gosto e sabor de terra ou mesmo de esgoto. Quanto ao desabastecimento, são descritos episódios pontuais, causados por paralisações curtas que duram dias, ou recorrentes, indicando deficiências crônicas da rede de distribuição. Tratam-se de problemas amplamentes noticiados na imprensa fluminense e carioca. Em alguns desses relatos, os usuários questionam o fato da cobrança ser mantida ainda que o fornecimento seja precário. Outros apontam gastos com outras fontes de água, tais como carro-pipa e água mineral, e solicitam abatimentos da conta.

De um modo geral, as reclamações relacionadas à cobrança são motivadas por aumentos inesperados e significativos da conta, que são tidas como indevidas ou abusivas. Alguns usuários apontam que os valores cobrados pressionam seus orçamentos familiares, ainda que seja oferecida a possibilidade de parcelamento dos débitos. São famílias cuja renda está comprometida seja pelo desemprego ou pelo emprego informal, seja pelos gastos com o cuidado de idosos ou pessoas enfermas. Atenta-se que a incapacidade de pagamento pode ocorrer por períodos curtos e pontuais, o que admite a possibilidade de renegociação e parcelamento de dívidas, caso a situação seja contornada. Todavia, caso a condição 
de pobreza perdure por longos períodos, é preciso prever ajuda constante a essas famílias

Nesses relatos, o funcionamento de hidrômetros, as leituras de medições realizadas pelos técnicos da concessionária e as trocas de equipamentos são questionados. Quando o consumo é estimado a partir de contas anteriores, abre-se a possibilidade de acordo pela companhia. Quando o consumo medido é registrado por hidrômetro, ela alega que não cabe a revisão dos valores e orienta o cliente a realizar minuciosa vistoria no ramal interno do imóvel, para verificar desperdícios ou perdas imperceptíveis.

Ao medir continuamente a água consumida, o hidrômetro possibilita a identificação de vazamentos ou de possíveis desvios clandestinos feitos na tubulação. Para a prestadora, é um instrumento chave no combate ao desperdício. Todavia, da forma como é adotado na cobrança, inflige aos usuários prejuízos antes de dar-lhes a possibilidade de solucionar o problema.

\section{CONCLUSÕES}

As plataformas de resolução de conflitos são vistas como ferramentas importantes de aproximação das empresas com seus clientes e possibilitam a condução ágil de acordos entre as partes. Judicializar significa levar mais tempo para resolver uma reclamação, mais custos e mais burocracia. Contar com os órgãos de defesa do consumidor e outros canais de atendimento permite resolver reclamações de forma mais rápida e menos litigiosa. Por outro viés, o registro das reclamações nestas plataformas, mesmo aquelas não resolvidas, se mostrou um banco de dados interessante para caracterizar a prestação do serviço de abastecimento de água.

No que se refere à cobrança, foi observado que as principais causas de insatisfação estão relacionadas a aumentos inesperados na conta de água, que levam à desconfiança nos mecanismos de medição do volume consumido e ao endividamento de famílias. As modalidades de cobrança por volume mínimo e por estimativa de consumo também foram objeto de críticas, sobretudo pela inalteração da cobrança mesmo quando o serviço ofertado é precário.

A partir da análise das plataformas de reclamações verificou-se que o serviço de abastecimento de água opera na lógica do consumo-cliente e, portanto, ao invés de ser vista como um serviço essencial, a água é tratada como uma mercadoria. Famílias contraem grandes dívidas em caso de problemas de fornecimento, logo ele passa a ser determinante para o reforço de desigualdades. É preciso subverter a lógica mercantil de que 'quanto mais água vendida melhor' e compreender que o atendimento pleno dos usuários, com água segura, a um preço acessível e ofertada sem interrupções, é o propósito maior dos operadores de sistemas de abastecimento de água.

\section{AGRADECIMENTOS}

O presente trabalho foi realizado com apoio da Coordenação de Aperfeiçoamento de Pessoal de Nível Superior Brasil (CAPES).

\section{REFERÊNCIAS}

ASSEMBLEIA LEGISLATIVA DO ESTADO DO RIO DE JANEIRO (2020). Comissão parlamentar de inquérito destinada a investigar irregularidades nas medições dos hidrômetros das concessionárias de água do estado do Rio de Janeiro e propor soluções. Diário Oficial do Estado do Rio de Janeiro (DOE-RJ). 11 de março de 2020, nº 045, parte II, p. 14-20. 2020.

BRASIL (2019). Ministério do Desenvolvimento Regional. Secretaria Nacional de Saneamento - SNS. Sistema Nacional de Informações sobre Saneamento: Diagnóstico dos Serviços de Água e Esgotos - 2019. Brasília: SNS/MDR, 2021. 

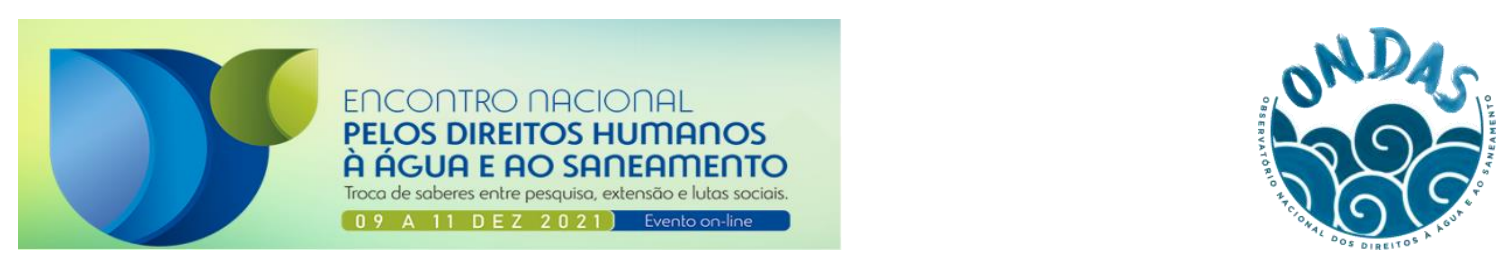

BROWN, C.; HELLER, L. Affordability in the provision of water and sanitation services: Evolving strategies and imperatives to realise human rights. International Journal of Water Governance. 5 (2), p.19-38. 2017.

CEDAE, 2018. Guia do usuário. 52 p. Disponível em: https://cedae.com.br/Portals/0/guia_2018.pdf Acesso em: 03/10/2021.

ORGANIZAÇÃO DAS NAÇÕES UNIDAS (2015). The human rights to safe drinking water and sanitation. Resolução da Assembleia Geral da ONU, Resolução 7/169, 6p.

RECLAME AQUI, 2021. Reclamações da empresa CEDAE - RJ no perído entre 01/10/2020 a 30/09/2021. Disponível em: https://www.reclameaqui.com.br/empresa/cedae-rj/ Acesso em: 05/10/2021

SENACON, 2021. Reclamações da empresa CEDAE - RJ no período entre 05/01/2021 a 17/09/2021. Disponível em: https://www.consumidor.gov.br/pages/indicador/relatos/abrir Acesso em 05/10/2021

SERASA, 2021. Mapa de inadimplência e renegociação de dívidas no Brasil. Maio/2021. Disponível em: https://www.serasa.com.br/ Acesso em: 10/10/2021. 